\title{
Pengaruh Iklan dan Public Relation Terhadap Citra Institusi Serta Keputusan Mahasiswa Memilih Kampus STIKI Malang Sebagai Tempat Studi
}

\author{
Yekti Asmoro Kanthi \\ Jurusan Manajemen Informatika Sekolah Tinggi Informatika dan Komputer Indonesia \\ E-mail :yektiasmoro@stiki.ac.id
}

\begin{abstract}
ABSTRAK. Periklanan dan public relation merupakan salah satu strategi pemasaran penerimaan mahasiswa baru di kampus STIKI Malang. Kedua strategi tersebut digunakan agar tepat sasaran dengan perubahan dan perkembangan teknologi yang semakin cangih diimbangi tingkat persaingan antar institusi pendidikan yang semakin meningkat. Media pemasaran diharapkan memberikan suatu kontribusi terhadap citra institusi dan keputusan pemilihan tempat studi lanjut bagi calon mahasiswa. Metode penelitian yang digunakan adalah analisis jalur dengan menggunakan instrumen kuesioner dan wawancara. Respondent dalam penelitian ini adalah seluruh mahasiswa STIKI Malang angkatan 2016 sebanyak 250 orang di empat program studi yaitu Teknik Informatika, Sistem Informasi, Manajemen Informasi dan Desain Komunikasi Visual. Hasil penelitian menunjukkan bahwa iklan berpengaruh signifikan terhadap citra institusi, public relation berpengaruh signifikan terhadap citra institusi, iklan berpengaruh tidak signifikan terhadap keputusan mahasiswa memilih STIKI sebagai tempat studi, public relation berpangaruh signifikan terhadap keputusan mahasiswa memilih STIKI sebagai tempat studi dan citra institusi berpengaruh signifikan terhadap keputusan mahasiswa memilih STIKI sebagai tempat studi.
\end{abstract}

Kata kunci : periklanan, public relation, citra institusi, keputusan memilih tempat studi

\begin{abstract}
Advertising and public relations is one of the student new admissions marketing strategy at campus STIKI Malang. Both strategies are used to be on target with increasingly changing technological changes and developments that are balanced by the increasing level of competition among educational institutions. Media marketing is expected to contribute to the institution's image and selection decisions for students. The research method used is path analysis by using questionnaires and interview instruments. Respondents in this study are all students STIKI Malang force 2016 as many as 250 people in four courses namely Informatics Engineering, Information Systems, Information Management and Visual Communication Design. The result shows that advertisement have significant effect to corporate image, public relation have significant effect to corporate image, advertisement have not significant to student decision choose STIKI as study place, public relation has significant effect to result STIKI as study place and student decision choose STIKI as study place.
\end{abstract}

Keywords :advertising,pupblic relation, corporate image, decision to choose the place of study

\section{PENDAHULUAN}

Tingginya persaingan antar institusi pendidikan saat ini mengharuskan setiap institusi untuk terus berinovasi dan kreatif dalam menyusun strategi pemasarannya. Strategi pemasaran merupakan salah satu cara intitusi dalam mempertahankan kelangsungan hidup, memperoleh laba, memperkuat posisi serta mengembangkan institusi dalam menghadapi persiangan (Khasanah, 2011). Strategi pemasaran yang dapat dilakukan yaitu melalui kegiatan promosi dan public relation yang dilakukan oleh institusi sehingga dapat meningkatkan citra institusi yang berpengaruh terhadap keputusan pembelian. (Wijaya, 2013)

Setiap instistusi pendidikan akan selalu berusaha mempertahankan dan menjaga keunggulan citra yang dimilikinya. Dalam hal ini yang dimaksud konsumen adalah mahasiswa yang belajar pada institusi pendidikan tersebut. Bila suatu perguruan tinggi memiliki citra yang posistif maka calon mahasiswa akan lebih memungkinkan untuk melakukan keputusan pembelian. (Dewanti, et al., 2010).

STIKI merupakan salah satu intitusi pendidikan yang memiliki citra sebagai perguruan tinggi berbasis IT. Dalam meningkatkan citra institusi, STIKI menggunakan media promosi baik yang bersifat online maupun offline. Media promosi yang digunakan yaitu periklanan danmarketing public relation untuk meningkatkan citra STIKI. Kegiatan periklanan dan public relation bertujuan untuk menginformasikan, membujuk, dan merekrut calon mahasiswa baru dilakukan melalui kerjasama dan layanan informasi ke sekolah, publikasi media massa (brosur, spanduk, iklan, dll.), media internal, dan website. Materi publikasi yang diberikan meliputi prestasi mahasiswa, prestasi institusi, kerjasama institusi dengan perguruan tinggi lain baik dalam negeri maupun luar negeri, sarana dan prasarana intitusi, serta program unggulan institusi. Semakin sering public relation STIKI 
mempromosikan keunggulan produk yang dimiliki, maka tidak menutup kemungkinan produk tersebut akan mendorong para calon mahasiswa untuk mencoba. Mahasiswa akan mendapatkan informasi-informasi mengenai keunggulan produk yang dipasarkan dan selanjutnya akan tertarik untuk mencobanya lalu memutuskan untuk memilih STIKI sebagai tempat studi lanjutnya.

Perbedaan penelitian ini dengan penelitian sebelumnya yaitu tempat penelitian yang dilakukan pada sector jasa. Penelitian sebelumnya yang dilakukan oleh Ampofo (2014), Oladepo \& Abimbola (2015), Gabriel \& Loredana (2012) meneliti pada sektor komoditas barang. Harapannya penelitian ini dapat bermanfaat bagi institusi yang bergerak di sektor jasa, sehingga dapat dijadikan referensi untuk media promosi yang digunakan untuk memasarkan jasa layanannya.

\section{TINJAUAN PUSTAKA}

\subsection{Iklan}

Promosi merupakan upaya untuk mengarahkan seseorang agar dapat mengenal produk suatu perusahaan, memahaminya, merubah sikap, menyukai, yakin, dan pada akhirnya melakukan pembelian dan selalu ingat akan produk tersebut dibenaknya. (Tjiptono, 2005) Proses promosi yang dilakukan untuk mengkomunikasikan variable permasaran untuk dilaksanakan oleh perusahaan atau institusi dalam memasarkan produknya. Media promosi yang bisa digunakan berupa periklanan berupa brosur, spanduk, baliho, video pengenalan, media internal, dan website.

Iklan merupakan suatu pesan menawarkan produk yang ditujukan konsumen melalui suatu media massa.(Kasali, 2007). Iklan berfungsi sebagai sarana komunikasi terhadap produk yang disampaikan melalui berbagai media dengan biaya pemrakarsa agar konsumen tertarik untuk mengikuti. (Pujiyanto, 2001) Iklan berfungsi ]untuk memperkuat dorongan kebutuhan dan keinginan konsumen terhadap suatu produk untuk mencapai pemenuhan kepuasannya.

Kotler \& Amstrong (2001) mengemukakan bahwasanya daya tarik iklan (attention) harus mempunyai tiga sifat yaitu pertama iklan harus bermakna (meaningful), menunjukkan manfaat manfaat yang membuat produk lebih diinginkan atau lebih menarik bagi konsumen. Kedua, pesan iklan harus dapat dipercaya (believable), konsumen percaya bahwa produk tersebut akan memberikan manfaat seperti yang dijanjikan dalam pesan iklan. Ketiga distinctive, bahwa pesan iklan lebih baik dibanding iklan merek pesaing. Assael $(2002,60)$ menjelaskan Interest yaitu munculnya minat beli konsumen tertarik terhadap objek yang dikenalkan oleh suatu pemasar. Desire yaitu tahap setelah merasa tertarik, timbul hasrat atau keinginan untuk memiliki objek produk tersebut.

\subsection{Public Relation}

Public relation merupakan salah satu upaya yang disengaja, direncanakan, dan berkesinambungan untuk membangun dan mempertahankan hubungan antara organisasi (individu) dan publiknya. Dapat diartikan bahwa public relation berhubungan dengan fungsi manajemen yang mengevaluasi sikap public, mengidentifikasi kebijakan dan prosedur dari individu atau organisasi dengan kepentingan public, serta merencanakan dan menjalankan program yang bertujuan mendapatkan pemahaman dan penerimaan public. (McCarthy, 2016). Harris dalam Ruslan (2006:245) mendefinisikan marketing public relations sebagai sebuah proses perencanaan dan pengevaluasian program-program yang dapat merangsang penjualan dan pelanggan. Salah satu alasan marketing public relations dibutuhkan adalah bauran promosi lainnya seperti advertising, sales promotion, dan personal selling belum cukup efektif dalam merebut perhatian konsumen dan pasar. Komponen utama dalam marketing public relations terdiri atas publikasi, acara, pemberian sponsor, berita, pidato, kegiatan layanan masyarakat, dan media identitas. (Kotler dan Keller, 2009)

\subsection{Citra Institusi}

Apabila dikembangkan dengan baik, maka periklanan dan program marketing public relationsakan menciptakan suatu kaitan emosional antara konsumen dengan perusahaan yang nantinya akan berdampak pada citra perusahaan. Menurut Jefkins (2003:22) citra perusahaan adalah citra dari suatu organisasi secara keseluruhan, jadi bukan sekedar citra atas produk atau layanannya. Untuk dapat memenangkan persaingan akibat semakin banyaknya pesaing, setiap perusahaan harus meningkatkan citra mereka yang telah ada dimata para pelanggan sehingga dapat mempengaruhi keputusan pembelian.

\subsection{Keputusan Pembelian}

Kotler dan Amstrong (2006) mengartikan perilaku konsumen sebagai perilaku pembelian konsumen akhir baik individu maupun rumah tangga yang membeli produk untuk konsumsi personal. Selain itu, Kotler (dalam Suciningtyas, 2012) menyatakan keputusan pembelian suatu produk dalam diri konsumen tidak terjadi begitu saja, tetapi membutuhkan suatu proses. Proses pengambilan keputusan untuk membeli suatu produk dimulai dari pengenalan masalah, pencarian informasi, evaluasi terhadap beberapa alternatif, yang selanjutnya akan tercipta suatu keputusan pembelian serta terbentuknya perilaku pasca pembelian. Keputusan konsumen dalam pembelian 
selain dipengaruhi oleh karakteristik konsumen, dapat dipengaruhi oleh rangsangan perusahaan yang mencakup produk, harga, tempat dan promosi. Variable tersebut saing mempengaruhi proses keputusan pembelian sehingga menghasilkan keputusan pembelian yang didasarkan pada pilihan produk, pilihan merek, pilihan penyalur, waktu pembelian dan jumlah pembelian.

\section{KERANGKA KONSEPTUAL DAN HIPOTESIS}

Kerangka konseptual dapat pada penelitian ini disajikan dalam Gambar 1.

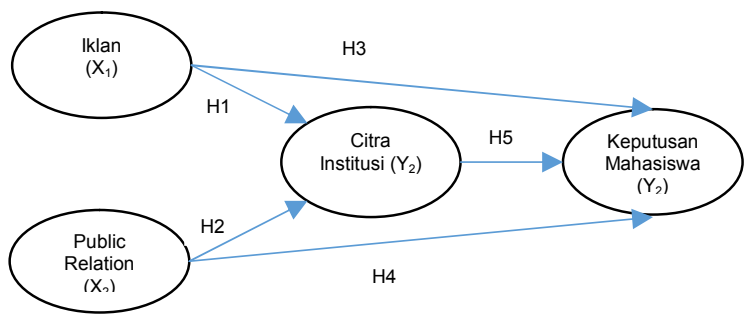

Gambar 1. Model Konseptual

H1: Iklan memiliki pengaruh terhadap citra institusi

$\mathrm{H}$ 2:Public relation memiliki pengaruh terhadap citra institusi

H3: Iklan memiliki pengaruh terhadap keputusan mahasiswa

H4: Public relation memiliki pengaruh terhadap keputusan mahasiswa

H5: Citra institusi memiliki pengaruh terhadap keputusan mahasiswa

\section{METODE PENELITIAN}

Jenis penelitian ini termasuk dalam penelitian eksplanatori (explanatory research) yaitu penelitian yang berupaya menjelaskan hubungan kausal antara variabel-variabel melalui pengujian hipotesis (Singarimbun dan Effendi, 2008). Lokasi penelitian ini dilaksanakan di Kampus STIKI Malang yang terletak di Jl. Raya Tidar 100.

Populasi penelitian sebanyak yaitu mahasiswa baru tahun 2016 sebanyak 250 orang. Dari populasi tersebut didapatkan jumlah sampel sebanyak 71 orang dengan menggunakan formulasi rumus Slovin. Jumulah sampel 71 orang tersebut dibagi lagi per program studi yang disajikan pada tabel 1 berikut.

Tabel 1. Pembagian Sampel Penelitian

\begin{tabular}{|c|c|c|}
\hline Program Studi & Populasi & Sampel \\
\hline TI & 120 & 34 \\
\hline SI & 24 & 7 \\
\hline MI & 20 & 6 \\
\hline DKV & 86 & 24 \\
\hline Jumlah & 250 & 71 \\
\hline
\end{tabular}

Tahapan pelaksanaan penelitian terdiri dari dua tahap yaitu penelitian lapang dan analisis data. Penelitian lapang dilakukan secara langsung di kampus STIKI Malang yang menjadi obyek penelitian. Penelitian lapang diperoleh dengan cara wawancara dan pembagian kuesioner pada responden penelitian.

Tahapan selanjutnya yaitu analisis data. Tahap analisis data terdiri dari 3 macam yaitu uji validitas dan reliabilitas, analisis data statistic deskriptif dan analisis data statistic inferensial. Tahap uji validitas dan uji reliabilitas berfungsi untuk menentukan data penelitian yang didapatkan valid dan reliable atau tidak. Sedangkan analisis statistic deskriptif digunakan untuk mengetahui ciri khas responden penelitian. Analisis statistic inferensial berfungsi sebagai pengukuran korelasi antar variabel.

\section{HASIL DAN PEMBAHASAN \\ 5.1 Hasil Analisis Inferensial}


Berdasarkan model empiris yang diajukan dalam penelitian ini, dilakukan analisis menggunakan analisis jalur. Analisis jalur merupakan metode untuk mempelajari pengaruh langsung dan tidak langsung diantara variabel-variabel penelitian. Hasil] uji regresi linear disajikan pada tabel 2.

Tabel 2. Hasil Uji Regresi

\begin{tabular}{|c|c|c|c|c|c|c|}
\hline $\begin{array}{c}\text { Variabel } \\
\text { Bebas }\end{array}$ & $\begin{array}{l}\text { Variabel } \\
\text { Terikat } \\
\end{array}$ & B & Beta & $\mathbf{T}$ & Sig & Ket. \\
\hline Iklan & $\begin{array}{c}\text { Citra } \\
\text { Institusi }\end{array}$ & 0,356 & 0,326 & 3,666 & 0,000 & Signifikan \\
\hline $\begin{array}{c}\text { Public } \\
\text { Relation }\end{array}$ & $\begin{array}{c}\text { Citra } \\
\text { Institusi }\end{array}$ & 0,676 & 0,557 & 6,268 & 0,000 & Signifikan \\
\hline $\begin{array}{c}\mathrm{R} \\
\mathrm{R}^{2} \\
\text { Adjusted } \mathrm{R}^{2} \\
\text { F hitung } \\
\text { Sig F }\end{array}$ & $\begin{array}{l}=0,7776 \\
=0,603 \\
=0,591 \\
=51,603 \\
=0,000\end{array}$ & & & & & \\
\hline Iklan & $\begin{array}{l}\text { Keputusan } \\
\text { Pembelian } \\
\end{array}$ & 0,005 & 0,004 & 0,051 & 0,960 & $\begin{array}{c}\text { Tidak } \\
\text { signifikan } \\
\end{array}$ \\
\hline $\begin{array}{c}\text { Public } \\
\text { Relation }\end{array}$ & $\begin{array}{l}\text { Keputusan } \\
\text { Pembelian }\end{array}$ & 0,479 & 0,317 & 3,575 & 0,001 & Signifikan \\
\hline $\begin{array}{c}\text { Citra } \\
\text { Institusi }\end{array}$ & $\begin{array}{l}\text { Keputusan } \\
\text { Pembelian }\end{array}$ & 0,759 & 0,609 & 6,331 & 0,000 & Signifikan \\
\hline $\begin{array}{c}\mathrm{R} \\
\mathrm{R}^{2} \\
\text { Adjusted } \mathrm{R}^{2} \\
\text { F hitung } \\
\text { Sig F }\end{array}$ & $\begin{array}{l}=0,868 \\
=0,754 \\
=0,743 \\
=63,455 \\
=0,000\end{array}$ & & & & & \\
\hline
\end{tabular}

\section{Hasil Pengujian Hipotesis H1}

Hipotesis $\mathrm{H} 1$ menyatakan bahwa terdapat pengaruh signifikan dari iklan terhadap citra institusi dengan koefisien jalur pada hubungan ini sebesar 0,326 dengan signifikansi 0,000. Sehingga dapat disimpulkan bahwa data penelitian mendukung hipotesis $\mathrm{H} 1$ yaitu iklan dapat meningkatkan citra institusi.

\section{Hasil Pengujian Hipotesis H2}

Hipotesis $\mathrm{H} 2$ menyatakan bahwa terdapat pengaruh signifikan dari public relation terhadap citra institusi dengan koefisien jalur pada hubungan ini sebesar 0,557 dengan signifikansi 0,000. Sehingga dapat disimpulkan bahwa data penelitian mendukung hipotesis $\mathrm{H} 2$ yaitu public relation dapat meningkatkan citra institusi.

\section{Hasil Pengujian Hipotesis $\mathrm{H3}$}

Hipotesis H3 menyatakan bahwa terdapat pengaruh signifikan dari iklan terhadap keputusan mahasiswa dengan koefisien jalur pada hubungan ini sebesar 0,004 dengan signifikansi 0,960. Sehingga dapat disimpulkan bahwa data penelitian mendukung hipotesis $\mathrm{H} 3$ yaitu iklan memiliki pengaruh tidak signifikan terhadap keputusan mahasiswa. Hal ini berarti iklan yang baik tidak dapat mempengaruhi keputusan mahasiswa dalam memilih suatu institusi untuk tempat studi lanjutnya.

\section{Hasil Pengujian Hipotesis $\mathrm{H} 4$}

Hipotesis $\mathrm{H} 4$ menyatakan bahwa terdapat pengaruh signifikan dari public relation terhadap keputusan mahasiswa dengan koefisien jalur pada hubungan ini sebesar 0,310 dengan signifikansi 0,001. Sehingga dapat disimpulkan bahwa data penelitian mendukung hipotesis $\mathrm{H} 4$ yaitu public relation dapat meningkatkan keputusan mahasiswa.

\section{Hasil Pengujian Hipotesis H5}

Hipotesis H5 menyatakan bahwa terdapat pengaruh signifikan dari citra institusi terhadap keputusan mahasiswa dengan koefisien jalur pada hubungan ini sebesar 0,609 dengan signifikansi 0,000. Sehingga dapat disimpulkan bahwa data penelitian mendukung hipotesis H5 yaitu citra institusi dapat meningkatkan keputusan mahasiswa. Hasil penelitian disajikan pada Gambar 2. 


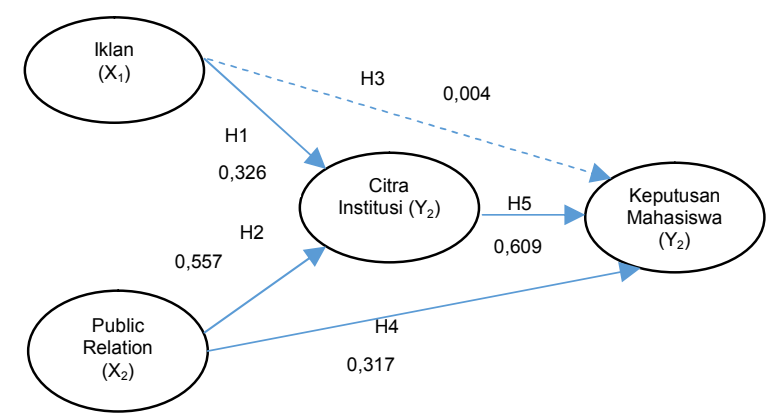

Gambar 2. Hasil penelitian

Pengaruh Langsung dan Pengaruh Tidak Langsung

Hasil penelitian dengan analisis jalur dapat terlihat bahwa ada salah satu variabel intervening yaitu variabel citra institusi. Variabel tersebut berfungsi untuk dapat melihat bagaimana pengaruh langsung dan pengaruh tidak langsung dalam model penelitian. Pengaruh langsung dan pengaruh tidak langsung dapat dibandingkan hasilnya dalam penelitian ini yang disajikan dalam tabel 3 berikut.

Tabel 3 Pengaruh Langsung dan Pengaruh Tidak Langsung

\begin{tabular}{|c|c|c|c|c|c|}
\hline $\begin{array}{c}\text { Variabel } \\
\text { Independen }\end{array}$ & $\begin{array}{c}\text { Variabel } \\
\text { Antara }\end{array}$ & $\begin{array}{c}\text { Variabel } \\
\text { Dependen }\end{array}$ & $\begin{array}{c}\text { Pengaruh } \\
\text { Langsung }\end{array}$ & $\begin{array}{c}\text { Pengaruh } \\
\text { Tidak } \\
\text { Langsung }\end{array}$ & $\begin{array}{c}\text { Pengaruh } \\
\text { Total }\end{array}$ \\
\hline Iklan $\left(\mathrm{X}_{1}\right)$ & - & $\begin{array}{c}\text { Citra } \\
\text { Institusi } \\
\left(\mathrm{Y}_{1}\right)\end{array}$ & 0,326 & - & - \\
\hline $\begin{array}{c}\text { Public } \\
\text { Relation }\left(\mathrm{X}_{2}\right)\end{array}$ & - & $\begin{array}{c}\text { Citra } \\
\text { Institusi } \\
\left(\mathrm{Y}_{1}\right)\end{array}$ & 0,557 & - & - \\
\hline Iklan $\left(\mathrm{X}_{1}\right)$ & $\begin{array}{c}\text { Citra } \\
\text { Institusi } \\
\left(\mathrm{Y}_{1}\right)\end{array}$ & $\begin{array}{c}\text { Keputusan } \\
\text { Mahasiswa } \\
\left(\mathrm{Y}_{2}\right)\end{array}$ & 0,004 & 0,198 & 0,202 \\
\hline $\begin{array}{c}\text { Public } \\
\text { Relation }\left(\mathrm{X}_{2}\right)\end{array}$ & $\begin{array}{c}\text { Citra } \\
\text { Institusi } \\
\left(\mathrm{Y}_{1}\right)\end{array}$ & $\begin{array}{c}\text { Keputusan } \\
\text { Mahasiswa } \\
\left(\mathrm{Y}_{2}\right)\end{array}$ & 0,317 & 0,339 & 0,656 \\
\hline $\begin{array}{c}\text { Citra Institusi } \\
\left(\mathrm{Y}_{1}\right)\end{array}$ & - & $\begin{array}{c}\text { Keputusan } \\
\text { Mahasiswa } \\
\left(\mathrm{Y}_{2}\right)\end{array}$ & 0,609 & - & - \\
\hline
\end{tabular}

Pada tabel 3 terlihat bahwa pengaruh tidak langsung melalui variabel intervening yaitu pengaruh iklan terhadap keputusan mahasiswa dengan variabel intervening citra institusi. Pengaruh langsung memberikan nilai sebesar 0,004 sedangkan pengaruh tidak langsung memberikan nilai sebesar 0,198 menghasilkan pengaruh total sebesar 0 ,202. Perlu diingat pula bahwa pengaruh langsung iklan terhadap keputusan mahasiswa secara langsung memberikan hasil yang tidak signifikan. Jika dibandingkan dengan pengaruh tidak langsung maka nilai yang diberikan lebih baik sehingga dapat disimpulkan bahwa pengaruh iklan terhadap keputusan mahasiswa secara tidak langsung memberikan hasil yang signifikan. Dengan demikian iklan yang baik dapat meningkatkan keputusan mahasiswa dalam memilih institusi untuk tempat studinya ditambah pula jika mahasiswa memperhatikan citra institusi.

\section{PENUTUP}

\subsection{Kesimpulan}

Berdasarkan analisis pembahasan hasil penelitian serta pengujian hipotesis yang dilakukan sebagaimana yang telah diuraikan maka diperoleh kesimpulan sebagai berikut :

1. Terdapat pengaruh signifikan antara variabel iklan terhadap citra institusi. Iklan yang baik dapat meningkatkan citra instusi. STIKI yang sudah memiliki citra sebagai kampus IT tertua di kota Malang dan lulusanya memiliki daya saing cukup tinggi dapat ditingkatkan kembali citranya dengan adanya presentasi iklan.

2. Terdapat pengaruh signifikan antara variabel public relation terhadap citra institusi. Tim public relation yang baik dalam penyampaian dan pelayanannya mampu meningkatkan citra institusi STIKI. Salah satu alasan marketing public relation dibutuhkan adalah bauran promosi seperti advertising, sales promotion dan personal selling belum cukup efektif dalam merebut perhatian konsumen dan pasar 
3. Terdapat pengaruh langsung yang tidak signifikan antara variabel iklan dan keputusan mahasiswa dalam melanjutkan studinya di STIKI. Iklan yang baik belum tentu dapat meningkatkan keputusan mahasiswa melanjutkan studinya di STIKI. Hal ini dikarenakan media promosi iklan melalui presentasi iklan belum cukup efektif untuk merubah minat dan daya Tarik masyarakat sehingga dibutuhakn media promosi secara face to face. Akan tetapi, jika diuji secara tidak langsung terdapat hasil signifikan antara variabel iklan dan keputusan mahasiswa melalui variabel antara citra instistusi.

4. Terdapat pengaruh langsung yang signifikan antara variabel public relation terhadap keputusan mahasiswa. Tim public relation yang baik terbukti dapat meningkatkan keputusan mahasiswa untuk memilih STIKI sebagai tempat untuk melanjutkan studinya. Media promosi face to face masih dianggap cukup efektif untuk mempengaruhi konsumen dalam mengambil keputusan pembelian. Berdasarkan hasil perhitungan pengaruh tidak langsung juga didapatkan hasil yang signifikan antara varaiebl public relation terhadap keputusan mahasiswa melalui variabel citra institusi.

5. Terdapat pengaruh signifikan antara variabel citra institusi terhadap keputusan mahasiswa. Citra institusi dibangun berdasarkan persepsi masyarakat. Citra institusi STIKI sebagai kampus IT tertua dengan menghasilkan lulusan yang kompeten mampu meningkatkan keputusan mahasiswa untuk melanjutkan studinya.

\subsection{Saran}

Penelitian ini dapat dikembangkan dengan beberapa variabel yang berhubungan dengan strategi pemasaran yaitu bauran pemasaran. Selain itu, penelitian itu juga dapat dikembangan dengan membandingkan hasilnya jika dilakukan di tempat penelitian lainnya yang sejenis di bidangnya.

\section{DAFTAR PUSTAKA}

Ampofo, Akwasi. (2014). Effects Of Advertising On Consumer Buying Behaviour : With Refrence to Demand for Cosmetic Products in Bangalore, India. ISSN 2224-3267 Vol. 27, 2014.

Assael. (2002). Consumer Behavior. New Jersey: Prentice - Hall, Inc.

Dewanti, R., Ismail, I., Tasrihanto, M. J., \& Prabowo, d. A. (2010). Analysis Of Influence Brand Trust And Brand Image Towards Purchase Decision The Private Label Product and Their Impact On Brand Loyality. International Journal of Bussiness Management 2 (2), pp : 1 - 19.

Gabriel, Dinu \& Dinu Loredana. (2012). The Impact Of Advertising On Consumer Behaviour In The Resita City Population. Proceedings of the $23^{\text {rd }}$ International DAAAM Symposium, Vol. 23, No. 1, ISSN 2304-1382

Jefkins, F. d. (2004). Public Relation Alih Bahasa : Haris Munandar. Jakarta: Penerbit Erlangga

Kasali, R. (2007). Manajemen Periklanan : Konsep dan Aplikasinya di Indonesia. Jakarta : PT Pustaka Utama Grafiti.

Khasanah, I. (2011). Pengaruh Atribut Produk, Bauran Promosi dan Kualitas Pelayanan Terhadap Keputusan Pembelian Produk Merchandise. Jurnal Asset 13 (1), pp : 155-163.

Kotler, P. a. (2009). Manajemen Pemasaran Jilid 1. Jakarta: Penerbit Erlangga .

Kotler, P. d. (2006). Dasar-dasar Pemasaran Jilid 2. Jakarta: Prehallindo.

Kumar, Prasanna \& K. Venkateswara Raju. (2013). The Role Of Advertising in Consumer Behaviour Decision Making. Journal of Bussiness and Management, Vol. 14, Issue 4, PP. 37-45.

Kuncoro, R. d. (2007). Cara Menggunakan dan Memakai Analisis Jalur (Path Analysis). Bandung : Alfabeta.

McCarthy, Breda. (2016).Consumer Behavioir and Public Relation. eBook auf www.talanx.com

Oladepo, Isaac \& Adunlami Sammuel Abimbola. The Influence Of Brand Image And Promotional Mix On Consumer Buying Decision - A Study Of Beverage Consumers In Lagos State, Nigeria. British Journal of Marketing Studies. Vol. 3, No. 4, PP. 97-109, 2015.

Pujiyanto. (2001). Periklanan. Malang: Universitas Negeri Malang.

Rochaety, E. R. (2007). Metodologi Penelitian Bisnis Dengan Aplikasi SPSS. Jakarta: Mitra Wacana Media .

Ruslan, R. (2006). Manajemen Public Relations dan Media Komunikasi : Konsepsi dan Aplikasi. Jakarta: Raja Grafindo Persada .

Singarimbun, M. d. (2008). Metode Penelitian Survei (Cetakan Ke Sembilan Belas). Jakarta : LP3ES.

Sudjana. (2002). Teknik Analisis Regresi dan Korelasi . Bandung : Tarsito.

Sujarweni, V. Wiratna. (2014). SPSS Untuk Penelitian. Yogyakarta : Pustaka Baru Press.

Sutojo, S. (2004). Membangun Citra Perusahaan . Jakarta: Damar Mulia Pustaka .

Tjiptono, F. (2005). Strategi Pemasaran Edisi 2. Yogyakarta: Andy Offset .

Wijaya, M. (2013). Promosi, Citra Merek, dan Saluran Distribusi Pengaruhnya terhadap Keputusan Pembelian Jasa Terminix di Kota Manado. EMBA 1 (4), pp : 105 - 114. 